\title{
Behaviour of Unsaturated Subgrade Soil Under Highway Load
}

\author{
Hanan Adnan Hassan Afaj ${ }^{1}$, Hadeel Amaar Mohammed ${ }^{1}$, Ghassan Nasser Jaffer ${ }^{2}$ \\ ${ }^{1}$ Department of Highway and Transportation Engineering, Al-Mustansiriayah University \\ ${ }^{2}$ General company for trade construction material, Baghdad, Iraq \\ ghassan_hanan@yahoo.com
}

\begin{abstract}
This paper studied the application of 2-D Plaxis (v8.6, 2011) software on a pavement layer structure set on unsaturated subgrade soil. An axisymmetric finite element (FE) model was used to analyze the behavior of pavement layers subjected to dynamic loadings. The model was loaded with an incremental contact pressure from 50 to $550 \mathrm{kPa}$ with different variable such as water table level (1,2 and $3 \mathrm{~m})$, suction of soil and degree of saturation $(100,90,80,70$ and 20\%). The results indicated that during loading on pavement layer with increases water table level and different degree of saturation the vertical settlement was decreased by about $(11,15$, and $18 \%)$ for water table level $=1 \mathrm{~m},(9,13,16 \%)$ for water table level $=2 \mathrm{~m}$ and $(28 \%)$ for water table level $=3 \mathrm{~m}$ (dry soil) respectively. The effect of degree of saturation on the vertical settlement is apparent at the lower value for water table level ( 1 and $2 \mathrm{~m}$ ) and the vertical settlement is decreased with increasing soil suction. The results also show the negative pore water pressure decreased with decreased of degree of saturation and development increases with depth and beginning of dynamic load. The effect of unsaturation greater at the center line of pavement layer and limited far away the center line.
\end{abstract}

Keywords: Unsaturated Soil, Soil Suction, Pavement, FE Analysis; Dynamic Loading.

\section{Paper History:}

(Received: 14/8/2017; Accepted: 30/10/2017)

\section{Introduction}

Compacted soils that are typically unsaturated with degrees of saturation varying from 75 to $90 \%$ are used in the pavements constructed. The negative pore-water pressure (soil suction) due to the presence of water in between soil particles has a significant effect on the pavement foundation stiffness and strength. At the time of construction the shear strength of the subgrade is high due to the negative pore-water pressures as such the highway has a high bearing capacity and functions as designed, the ingress of water with time into the weakest part of the pavement structure (subgrade) result an increase in the roughness index of the pavement surface due to volume change and distortion of the subgrade soils [1] [2] [3] [4] [5] [6] [7].

Pavement structure would constructed to support loads induced by movement vehicle loading and to distribute them safely to the subgrade soil, this is reflected in progressions on stress, strain and vertical deflection in each of the pavement layers. Figure 1 indicates the distribution of stress with depth [8]. There are critical values that occur at specific areas inside the structure. These effect the pavement, essentially influencing its performance [9]. The effect of a moving load on the pavement is a resultant development of vertical stresses, shear stresses, bending stresses and strains in each layer of the pavement.

The vertical loading that is dissipated through the wheel of the moving vehicles causes compressive stress in the pavement structure. While the stresses lead to permanent deformation and therefore rutting on the pavement surface. The rate of deformation is dependent on the characteristics of strength for the pavement materials [8]. 


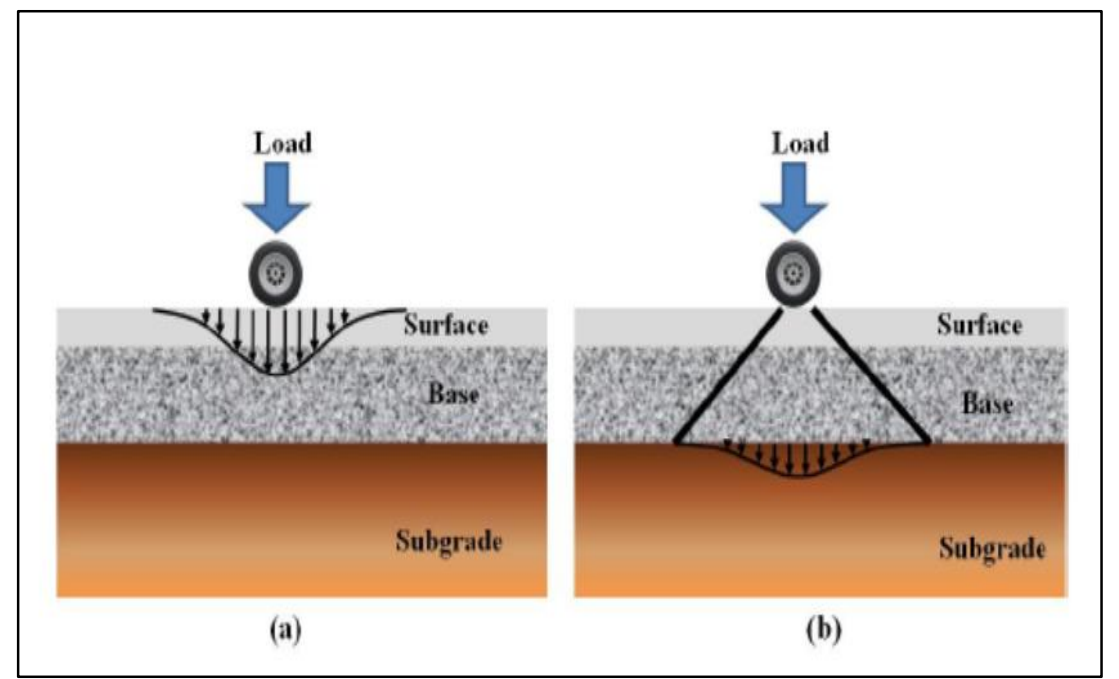

Figure 1: Stress Distributions with Depth in a Flexible pavement. a. High Stress Area Directly under Wheel Load. b. Reduced Load at Subgrade Lev

In this study, an attempt has been made to investigate the influence of soil suction, degree of saturation and change in water table on the behavior of unsaturated subgrade soil within the asphalt concrete pavement through the application of 2D Plaxis software program.

\section{Soil Suction Concept:}

In general, porous materials have a fundamental ability to attract and retain water. The existence of this fundamental property in soils is described in engineering terms as suction or negative stress in the pore water. In engineering practice, soil suction is composed of two components: matric and osmotic suction [1]. The sum of matric and osmotic suction is called total suction. Matric suction comes from the capillarity, texture, and surface adsorptive forces of the soil. Osmotic suction arises from the dissolved salts contained in the soil water. This relationship can be formed in an equation as follows:

$\mathrm{h}_{\mathrm{t}}=\mathrm{h}_{\mathrm{m}}+\mathrm{h}_{\pi}$

where $h_{t}=$ total suction $(\mathrm{kPa})$,

$\mathrm{h}_{\mathrm{m}}=$ matric suction $(\mathrm{kPa})$, and

$\mathrm{h}_{\pi}=$ osmotic suction $(\mathrm{kPa})$.

Total suction can be calculated by using Kelvin's equation, which is derived from the ideal gas law using the principles of thermodynamics and is given as:

$\mathrm{h}_{\mathrm{t}}=\frac{\mathrm{RT}}{\mathrm{V}} \ln \left(\frac{\mathrm{P}}{\mathrm{P}_{\mathrm{o}}}\right)$

where $R=$ universal gas constant,

$T=$ absolute temperature,

$V=$ molecular volume of water,
$P / P_{o}=$ relative humidity,

$P=$ partial pressure of pore water vapor,and

$P_{o}=$ saturation pressure of water vapor over a flat surface of pure water at the same temperature.

It should be noted that these two forms of soil suction are completely independent and have no effect on each other. If the soil is granular and free of salt, there is no osmotic suction and matric and total suction are equal. However clays contain salts and these salts cause a reduction in the vapour pressure. This results in an increase in the total suction, and this increase is the energy needed to transfer water into the vapour phase (i.e. the osmotic suction) [10].

\section{Computer Program and Constitutive Models:}

\subsection{Description of the Problem}

Plaxis (2D, v8.6, 2011) is a finite element application specifically intended for the analysis of deformation and stability in geotechnical engineering projects. Its comprehensive formulation makes it possible to analyze both simple and highly complex problems.

A typical pavement system consists of hot-mix asphalt layer, sub-base layer and unsaturated subgrade layer. The unsaturated soils of many areas in the central part of Iraq are composed of silty clay and clays soil. A representative area located at Baghdad city Al-Rusafa region; namely, Bab Al - Muadham, the site covers an area of soil contains silt and clay. The problem is selected from the work of [11]. Undisturbed samples are taken from (3.5) m depth below the natural ground surface, and then the soil sample are taken to the Soil Mechanic Laboratory, where subjected to a series of physical soil testing. 
The model considered where total thickness of the pavement is $0.3 \mathrm{~m}$, the thickness of subgrade soil $3 \mathrm{~m}$ is overlaid by a $0.20 \mathrm{~m}$ layer of Al-Nibaee aggregate as sub-base, and $0.1 \mathrm{~m}$ asphalt concrete on top as shown in Figure 2. The load is applied as uniform pressure acting on a circular area of radius $(0.2 \mathrm{~m})$ applied pressure values were: 50 , $100,200,300,400,500$, and $550 \mathrm{kPa}$.

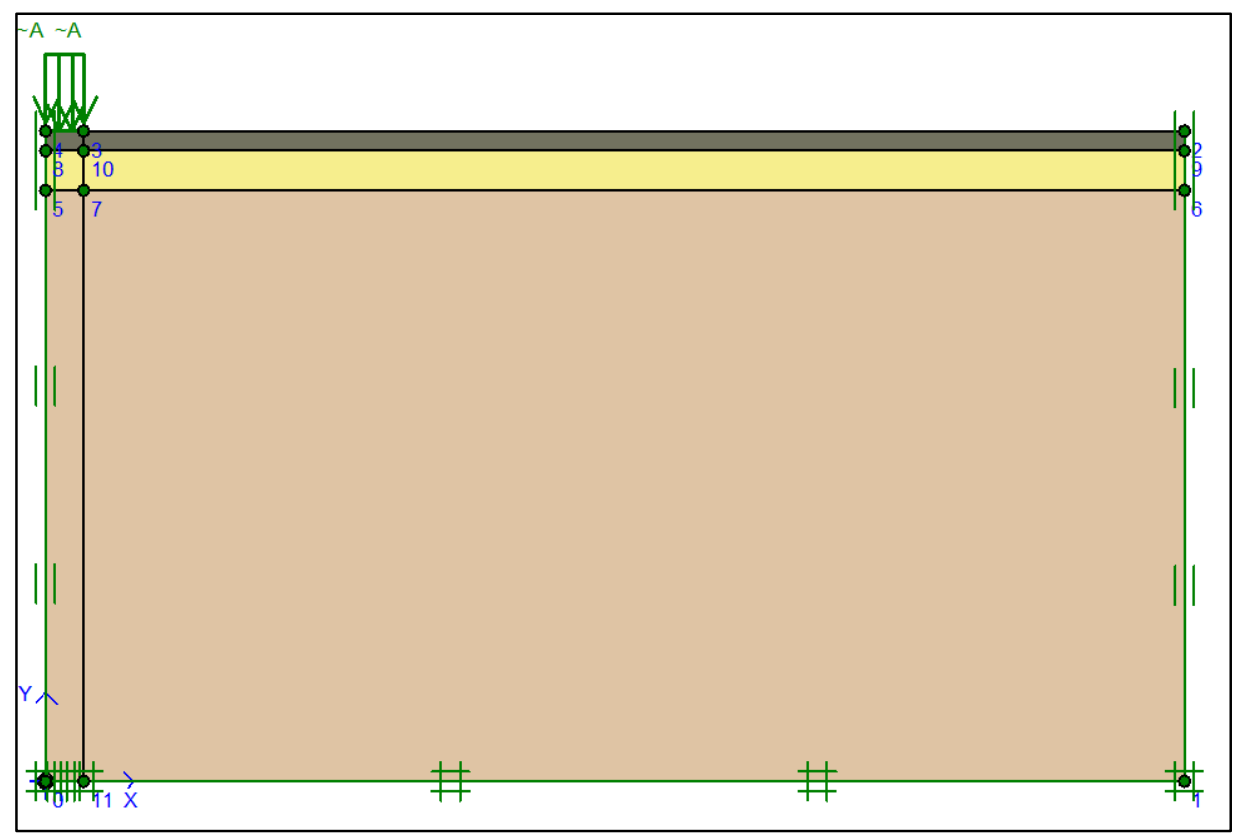

Figure 2: Finite element axisymmetric model for pavement

An axisymmetric model was utilized in the analysis using 15-noded structural solid element with medium refinement. Axisymmetric modeling was chosen in this study because it could simulate circular loading and did not require excessive computational time under dynamic loading [13, 14]. Alex [15] indicted that the nodal radial strains were assumed to be negligible at approximately10 times $\mathrm{R}$ (radius of loaded area) from the area applied wheel load. Also, the nodal stresses and displacements were assumed to be negligible at 20 times $\mathrm{R}$ below the pavement surface. Therefore, the width of the model was set at $6 \mathrm{~m}$ that equal 30 times $\mathrm{R}$ of loaded area [14], and the total thickness of model is $3.3 \mathrm{~m}$. The bottom of model was fixed in both vertical and horizontal directions. Both edges of the models were restricted against horizontal movement. In addition, the side and bottom boundaries are assumed to be impermeable, i.e. no flow is allowed through these sides. The finite element mesh is illustrated in Figure 3 due to symmetry, 736 elements are used for modeling half of the pavement layer.

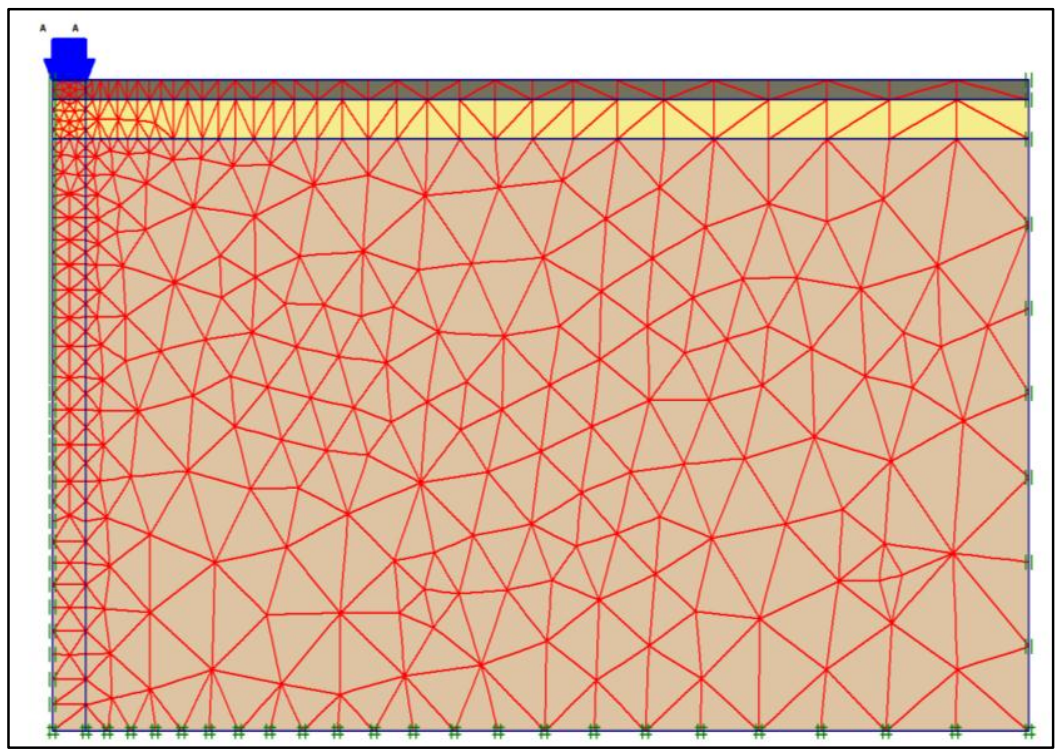

Figure 3: finite element mesh of pavement layer system 
3.2 Material Properties and constitutive models

\subsection{1 subgrade Soil layer}

The subgrade soil layer properties used in the model is shown in Table 1 , the particle size distribution of the soil is illustrated in Figure 4 [11].

Table 1 Physical properties for the subgrade soil layer [11].

\begin{tabular}{|c|c|}
\hline Parameter & Value \\
\hline LiquidLimit, LL $(\%)$ & 54 \\
\hline Plastic Limit, PL $(\%)$ & 27 \\
\hline Plasticity Index, PI $(\%)$ & 27 \\
\hline Specific Gravity, $\left(\mathrm{G}_{\mathrm{s}}\right)$ & 2.78 \\
\hline Total unit weight, $\left(\gamma_{\mathrm{t}}\right)\left(\mathrm{kN} / \mathrm{m}^{3}\right)$ & 18.82 \\
\hline Dry unit weight, $\left(\gamma_{\mathrm{d}}\right)\left(\mathrm{kN} / \mathrm{m}^{3}\right)$ & 14.33 \\
\hline Angle of internal friction, $(\varnothing)$ & 0 \\
\hline Poisson's ratio, $(v)^{*}$ for saturated soil & 0.45 \\
\hline Poisson's ratio, $(v)^{*}$ for unsaturated soil & 0.3 \\
\hline Hydraulic conductivity, $\left(k_{\mathrm{s}}\right)(\mathrm{m} / \mathrm{sec})$ & $2.85 \times 10^{-10}$ \\
\hline Void ratio, $(\mathrm{e})$ & 0.903 \\
\hline Coefficient of volume change $\left(m_{v}\right)\left(\mathrm{m}^{2} / \mathrm{MN}\right)$ & 0.716 \\
\hline Natural Water Content, $\mathrm{W}(\%)$ & 31.3 \\
\hline Degree of Saturation, $\mathrm{S}(\%)$ & 96 \\
\hline$\%$ Clay & 80.3 \\
\hline
\end{tabular}

*Assumed values [12]

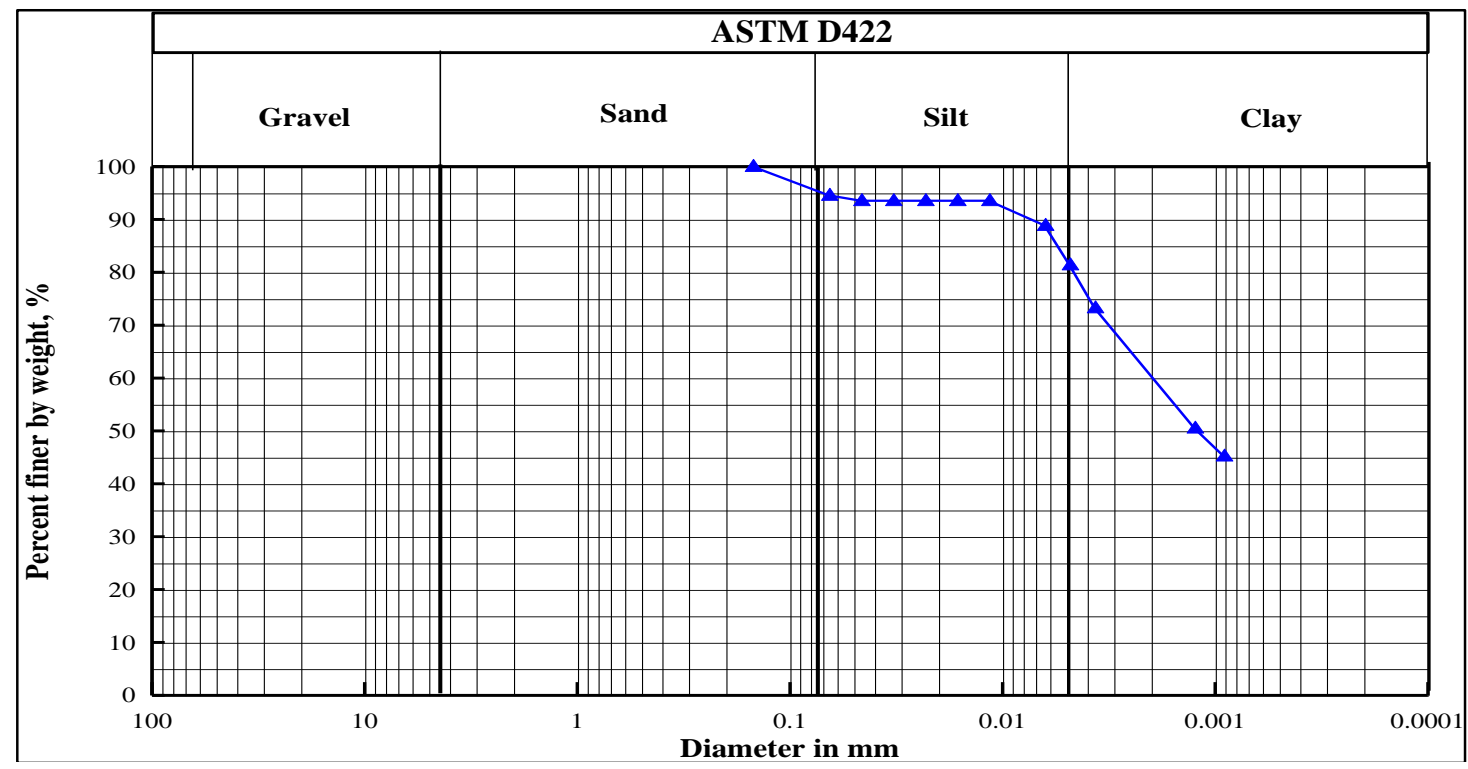

Figure 4: Grain size distribution of the soil [11]

Table 2 shows the undrained shear strength $\left(\mathrm{C}_{\mathrm{u}}\right)$ and the initial tangent modulus of elasticity $(\mathrm{E})$ of the subgrade soil for different degree of saturation.

Total and matric suction of the subgrade soil sample different degrees of saturation $(90 \%, 80 \%$,
$70 \%$, and 20\%) shown in Table 3, the soil water characteristic curve (relation between the gravitation water content and the matric suction) shown in Figure 5 [11]. 
Table 2 Results of unconfined compression test on remolded samples at different degrees of saturation [11].

\begin{tabular}{|c|c|c|c|}
\hline $\mathbf{S}(\boldsymbol{\%})$ & $\mathbf{q u}(\mathbf{k P a})$ & $\mathbf{c}_{\mathbf{u}}(\mathbf{k P a})$ & $\mathbf{E}(\mathbf{k P a})$ \\
\hline $100 \%$ & 130 & 65 & 52000 \\
\hline $90 \%$ & 151 & 75.5 & 60400 \\
\hline $80 \%$ & 164 & 82 & 65600 \\
\hline $70 \%$ & 176 & 88 & 70400 \\
\hline $20 \%$ & 256 & 128 & 102400 \\
\hline
\end{tabular}

Table 3 Results of soil suction and permeability coefficient at different degrees of saturation, [11].

\begin{tabular}{|c|c|c|}
\hline $\mathrm{S}(\%)$ & Matric suction $(\mathrm{kPa})$ & $\mathrm{k}(\mathrm{m} / \mathrm{sec})$ \\
\hline $100 \%$ & 50 & $2.85 \times 10^{-10}$ \\
\hline $90 \%$ & 150 & $2.33 \times 10^{-10}$ \\
\hline $80 \%$ & 480 & $333 \times 10^{-11}$ \\
\hline $70 \%$ & 1000 & $8.33 \times 10^{-12}$ \\
\hline $20 \%$ & 6310 & $2.35 \times 10^{-12}$ \\
\hline
\end{tabular}

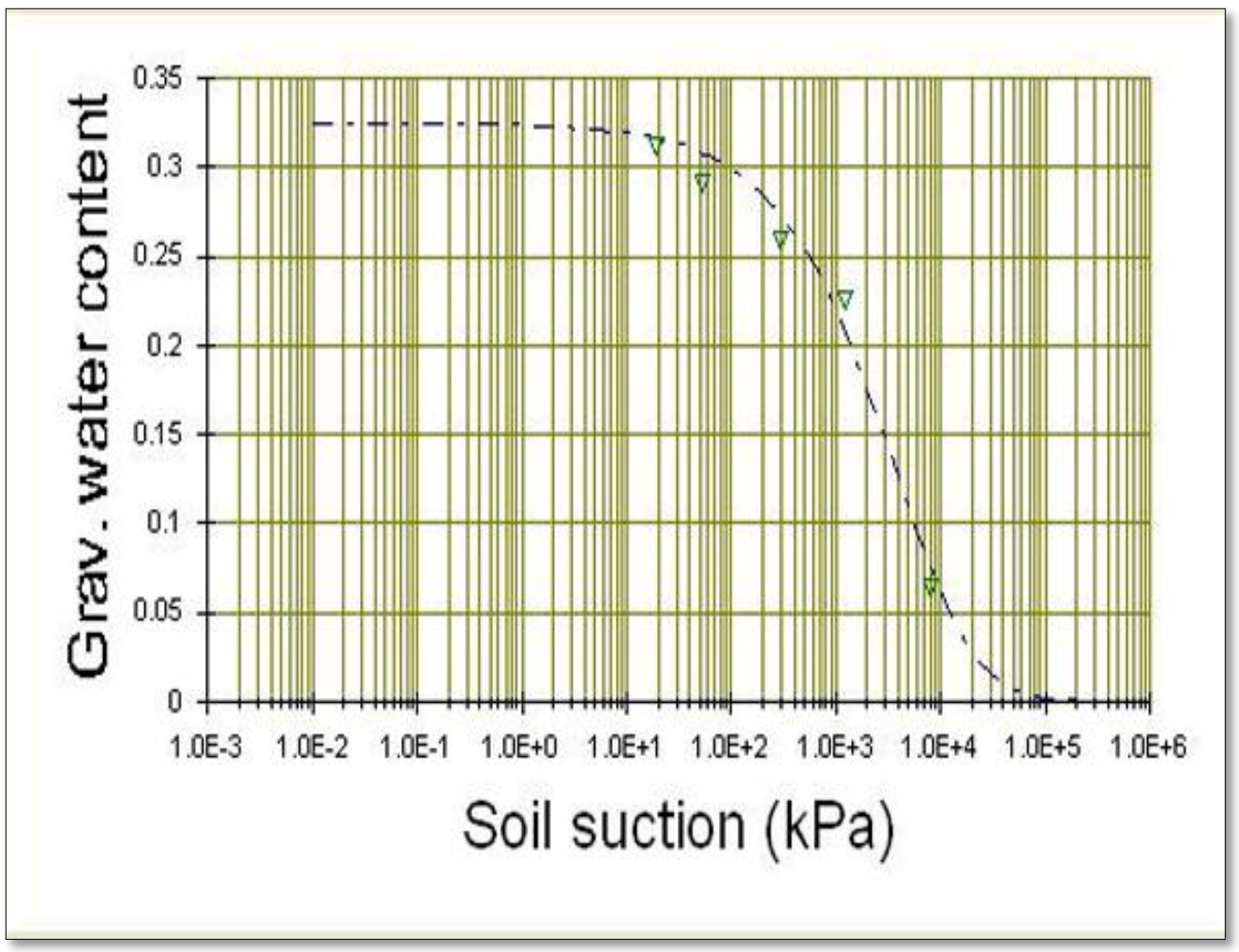

Figure 5: Relationships between the gravitational water content and the matric suction for the subgrade soils obtained by the program Soil Vision using Van Genuchten, [11]

\subsection{2 sub-base and Asphalt layer}

The properties of sub-base and asphalt layer used in the model are shown in Table (4), these inputs have been created by laboratory test. 
Table 4 Sub-base and asphalt layer properties.

\begin{tabular}{|c|c|c|}
\hline parameter & sub-base & asphalt \\
\hline Cohesion $(\mathrm{c}, \mathrm{kPa})$ & 5 & - \\
\hline Angle of internal friction, $(\varnothing)$ & 40 & - \\
\hline saturated unit weight, $\left(\gamma_{\mathrm{sat}}\right)\left(\mathrm{kN} / \mathrm{m}^{3}\right)$ & 22 & - \\
\hline Dry unit weight, $\left(\gamma_{\mathrm{d}}\right)\left(\mathrm{kN} / \mathrm{m}^{3}\right)$ & 20 & 22 \\
\hline Poisson's ratio, $(v)$ & 0.3 & 0.35 \\
\hline Permeability coefficient, $(k)(\mathrm{m} / \mathrm{sec})$ & 0.0001 & \\
\hline modulus of elasticity $(\mathrm{E}, \mathrm{kPa})$ & 50000 & 508000 \\
\hline
\end{tabular}

In this work, two constitutive models were used to characterize the load settlement and time settlement relations of the unsaturated subgrade soil under dynamic load. Linear elastic model was used for the asphalt layer while elastic plastic with Mohr-Coulomb failure under undrained condition for unsaturated subgrade soil layer and drained condition for sub-base layer.

\section{Results and Discussion}

Dynamic analysis is performed using Plaxis software (Plaxis v8.6). A half-sine pulse dynamic load was applied with amplitudes 50, 100, 200, $300,400,500$, and $550 \mathrm{kPa}$. Figure 6 shows dynamic load sample pulse for case of duration time $=0.10 \mathrm{~s}$, frequency $=5 \mathrm{~Hz}$ and load amplitude $=550 \mathrm{kPa}$. The magnitude, shape, and duration of such a pulse may vary with the stiffness of pavement, wheel load magnitude, its speed, and the depth of the study point. The halfsine pulse is widely used by many researchers to simulate a moving load on pavement surface. Kazemien et. al. (2010) [13] evaluated the dynamic response of multilayer pavement system using half-sine load pulse of $0.03 \mathrm{sec}$ duration.

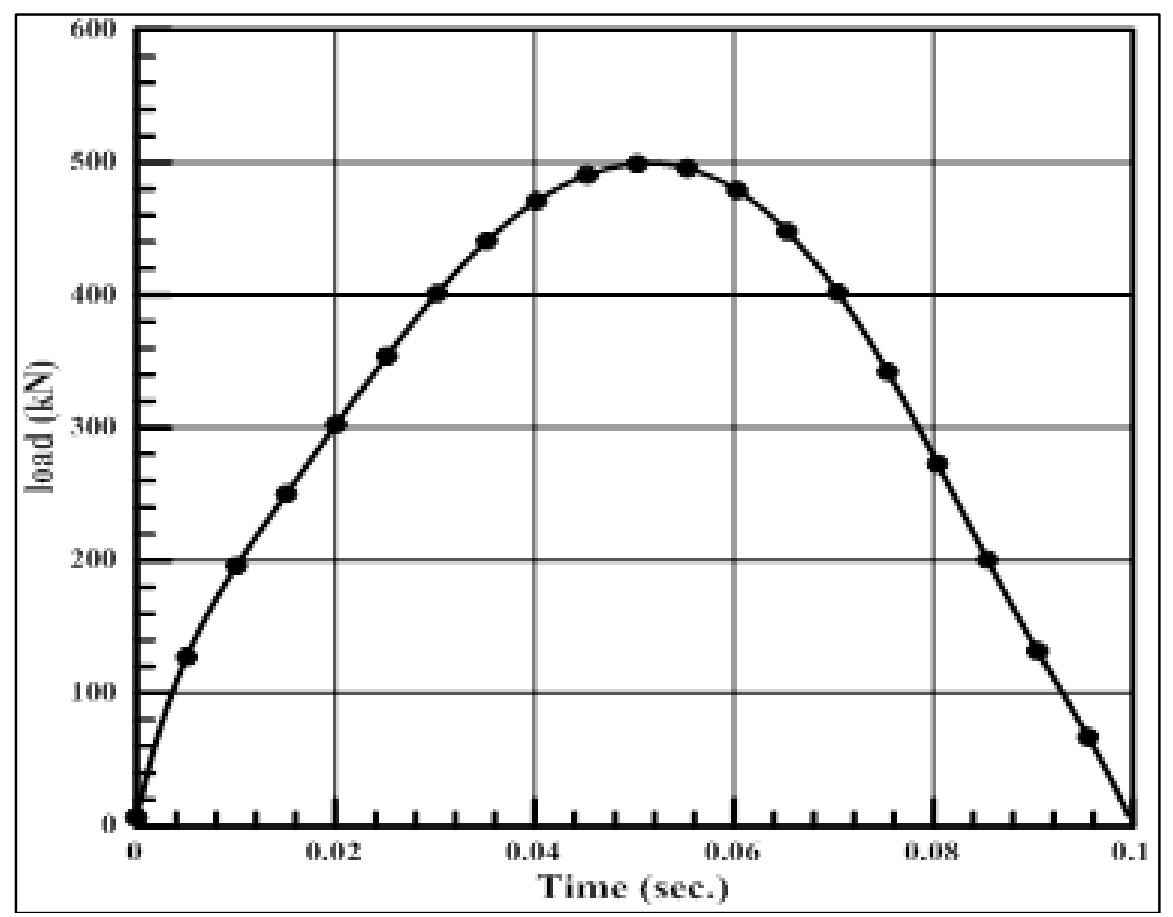

Figure 6: dynamic load pulse, duration $=0.1 \mathrm{sec}$, amplitude $=550 \mathrm{kPa}$, frequency $=5 \mathrm{~Hz}$

\subsection{Time - settlement relationship}

Figures 7 and 8 show the relationship between dynamic time and the vertical settlement in the point (A) at center line under the load for different water table and degree of consolidation. It can be noticed that the vertical settlement closely similar at the beginning time, then increased with time and decreased as the degree of saturation decreased for water level depth $1 \mathrm{~m}$ and $2 \mathrm{~m}$. This can be attributed to increasing in matric suction due to increasing unsaturated zone. 


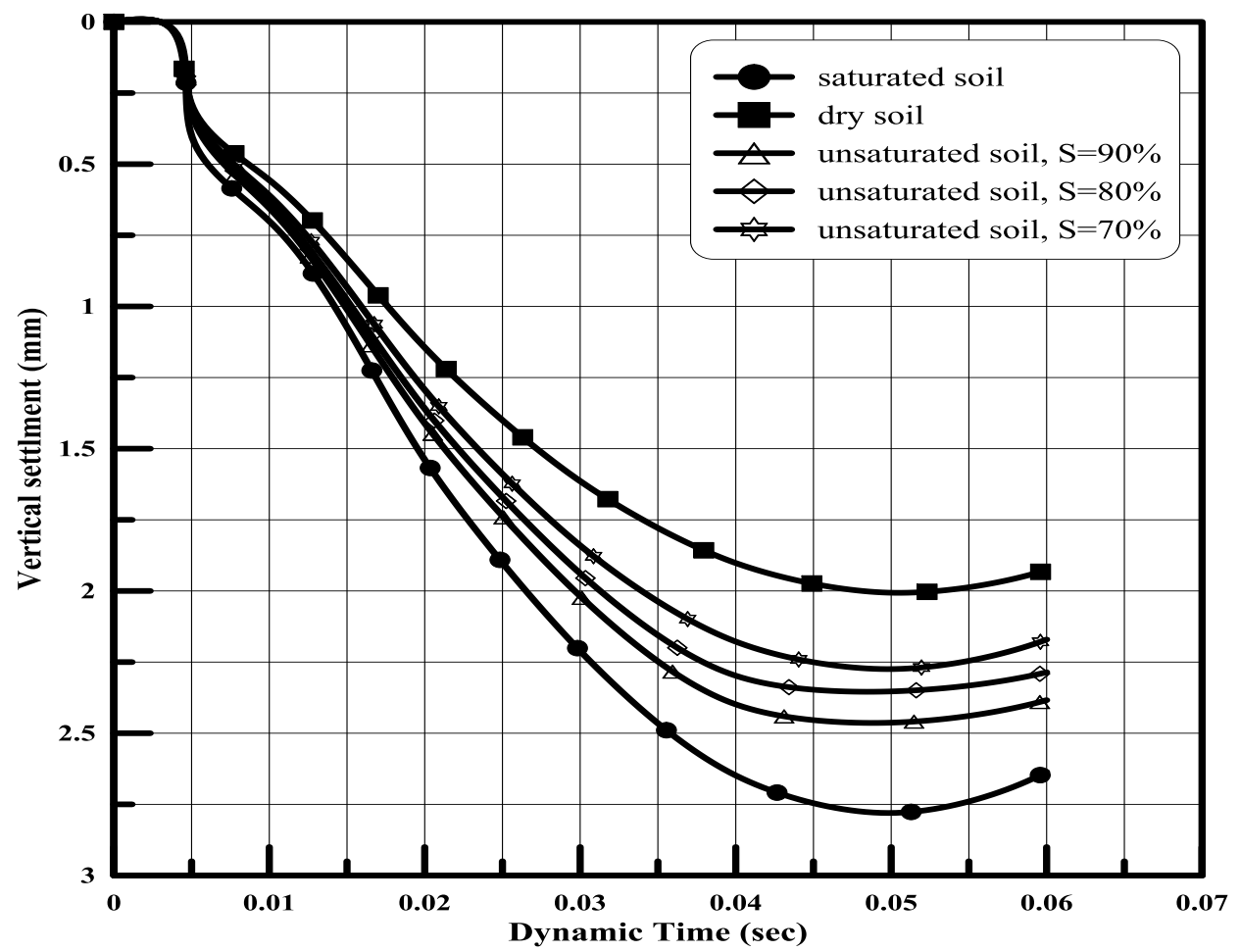

Figure 7: maximum vertical settlement for pavement system layer with dynamic time for water depth = $1 \mathrm{~m}$

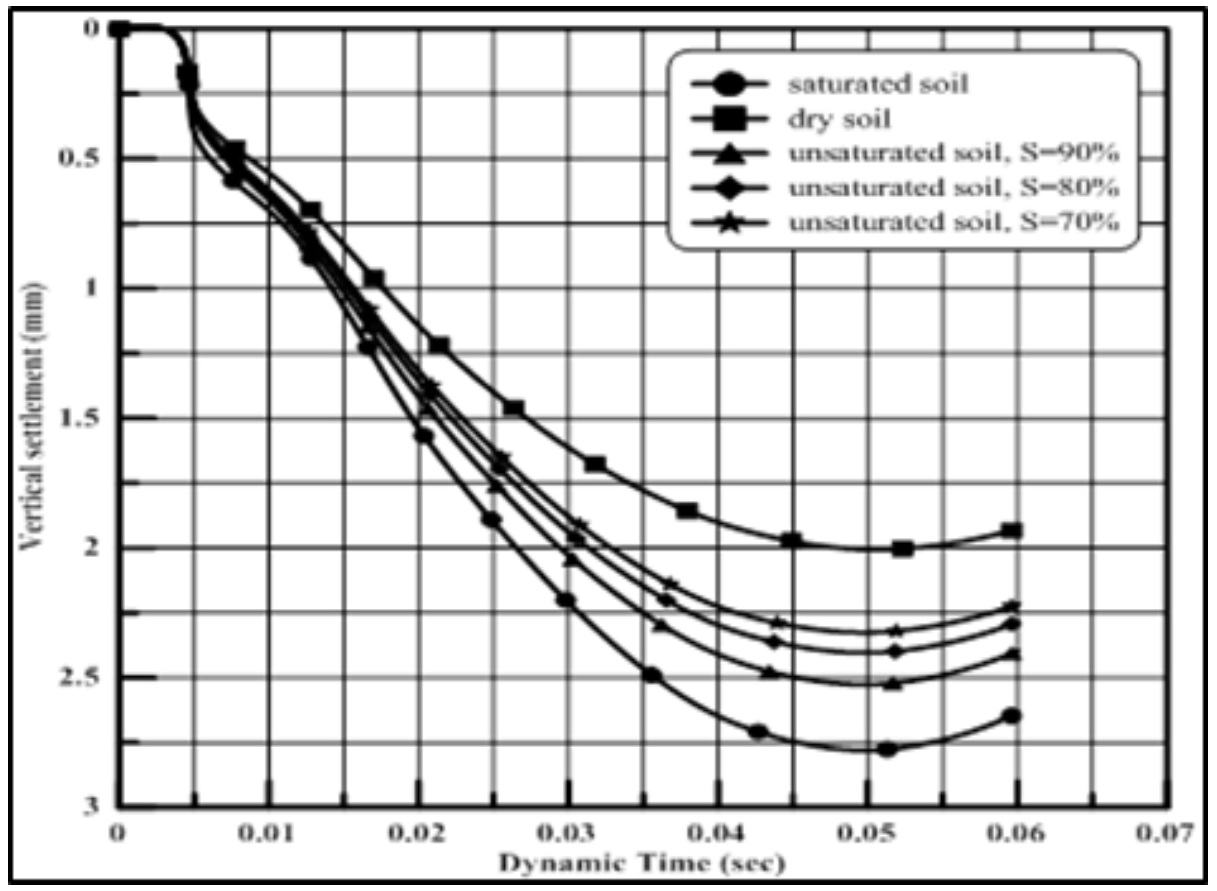

Figure 8: maximum vertical settlement for pavement system layer with dynamic time for water depth $=\mathbf{2} \mathbf{m}$

\subsection{Applied stress - settlement relationship}

Figures 9 and 10 show the relationship between applied stress and the vertical settlement in the point (A) for different water table and degree of consolidation. It can be seen that the vertical settlement increased linearly with applied stress and the degree of saturation for water level depth $1 \mathrm{~m}$ and $2 \mathrm{~m}$. This increase is due to the matric suction and effective pressure due to lowering of water level. The increase in vertical settlement was closed at the beginning of applied load until reached $200 \mathrm{kPa}$ then the change became slightly for $(S=70,80$, and $90 \%)$ specially for water level $1 \mathrm{~m}$, This may be attributed to the concentration of applied stress and to small contribution of matric suction while high increased when the soil change from dry $(\mathrm{S}=$ 
$20 \%)$ to saturated $(\mathrm{S}=100 \%)$ condition and increased in applied stress.

\subsection{Degree of saturation- settlement relationship}

The effect of degree of saturation on the vertical settlement in the point (A) for water level increase above $\mathrm{S}=70 \%$, this is may be due to the higher void ratio in the soil sample. Slightly increased in vertical settlement when the water level lowering from $2 \mathrm{~m}$ to $1 \mathrm{~m}$ the change is about $(2.3 \%)$ for each degree of saturation.

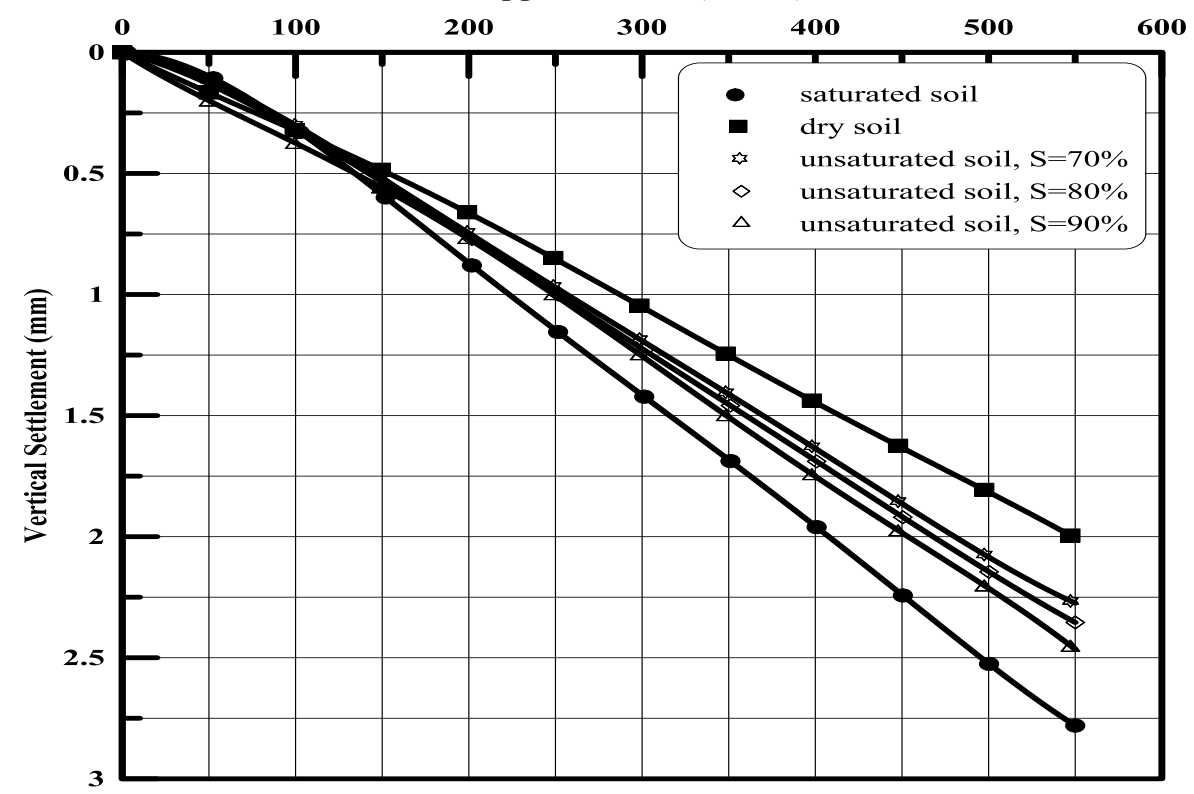

Figure 9: maximum vertical settlement for pavement system layer with applied stress for water depth = 1

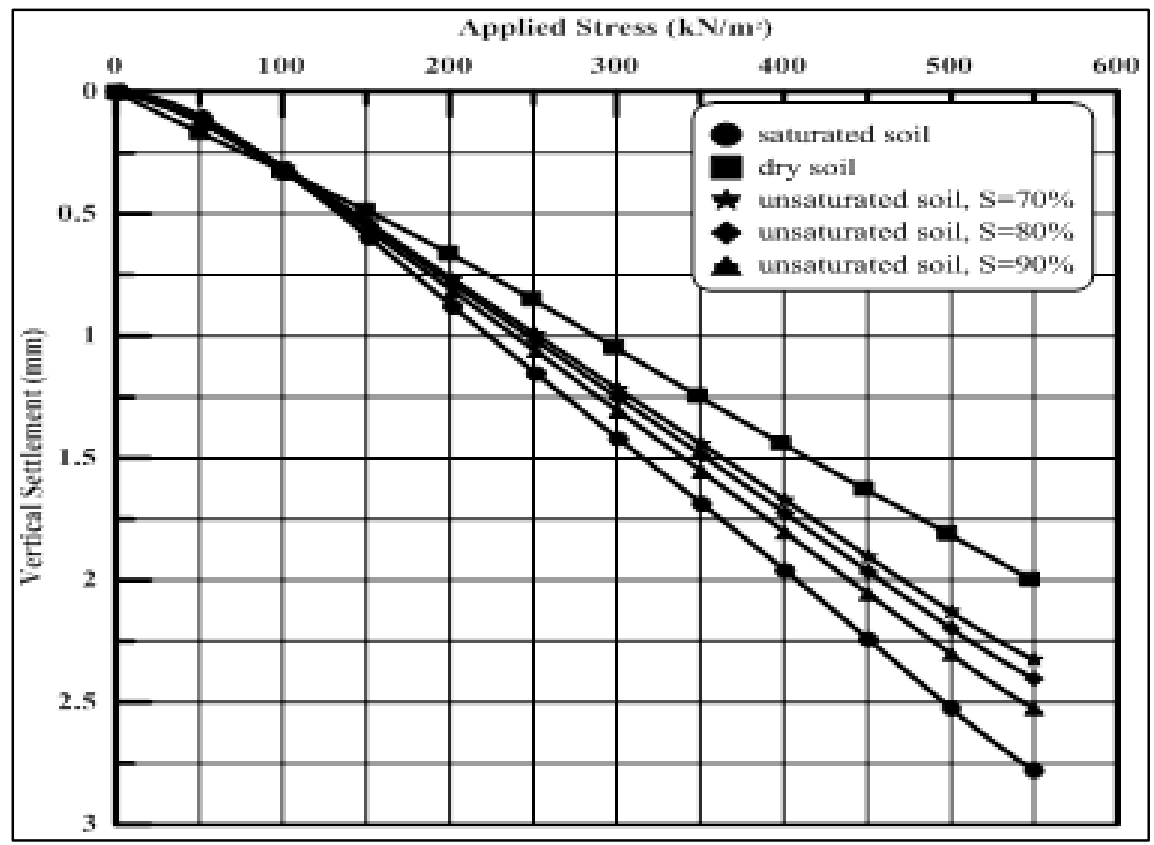

Figure 10: maximum vertical settlement for pavement system layer with applied stress for water depth = 2 m 


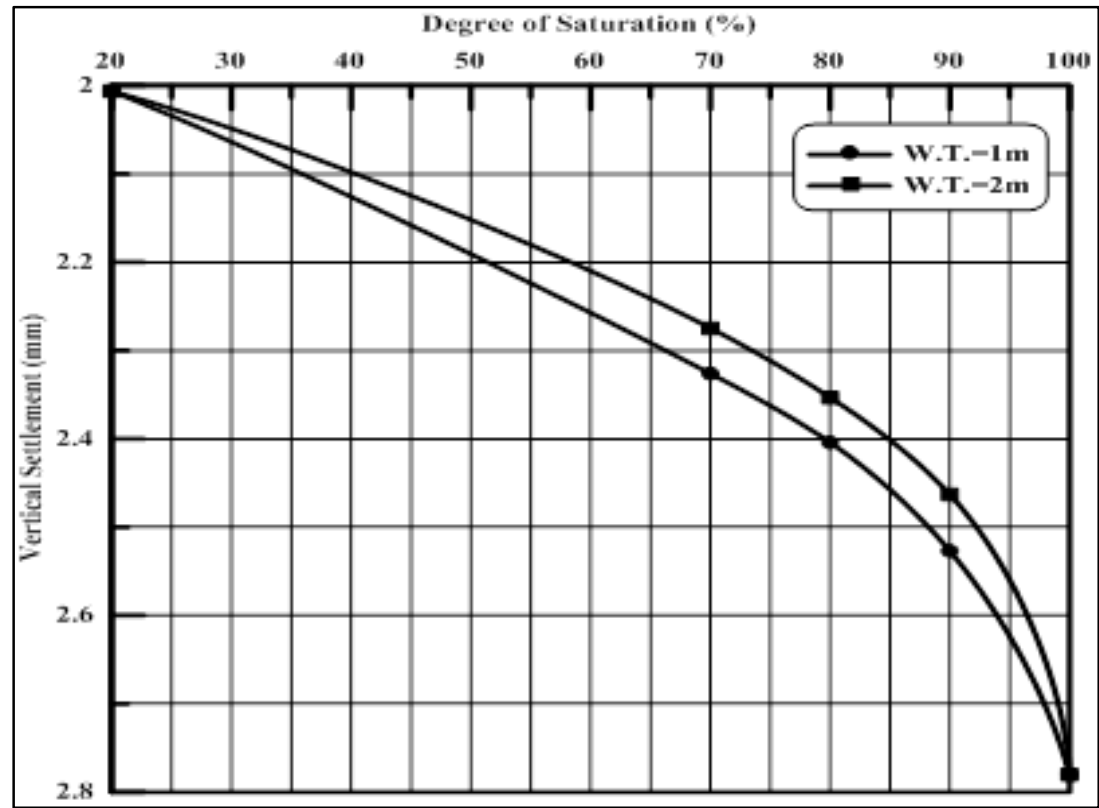

Figure 11: maximum vertical settlement for pavement system layer with degree of saturation for water depth $=2 \mathrm{~m}, 1 \mathrm{~m}$

$1 \mathrm{~m}$ and $2 \mathrm{~m}$ was shown in Figure 11 . Generally a straight line with the degree of saturation between (20 and $70 \%$ ) for both water level then nonlinear

\section{4 soil suction - settlement relationship}

The relationship between soil suction and the vertical settlement in the point (A) for water level
$1 \mathrm{~m}$ and $2 \mathrm{~m}$ was shown in Figure 12. The vertical settlement is decreased with increasing soil suction until reached closed value. The increase in the water content results in the decrease in the matric suction and the shear resistance at the contact point between soil particles, thereby decreasing the internal friction angle and increasing vertical settlement.

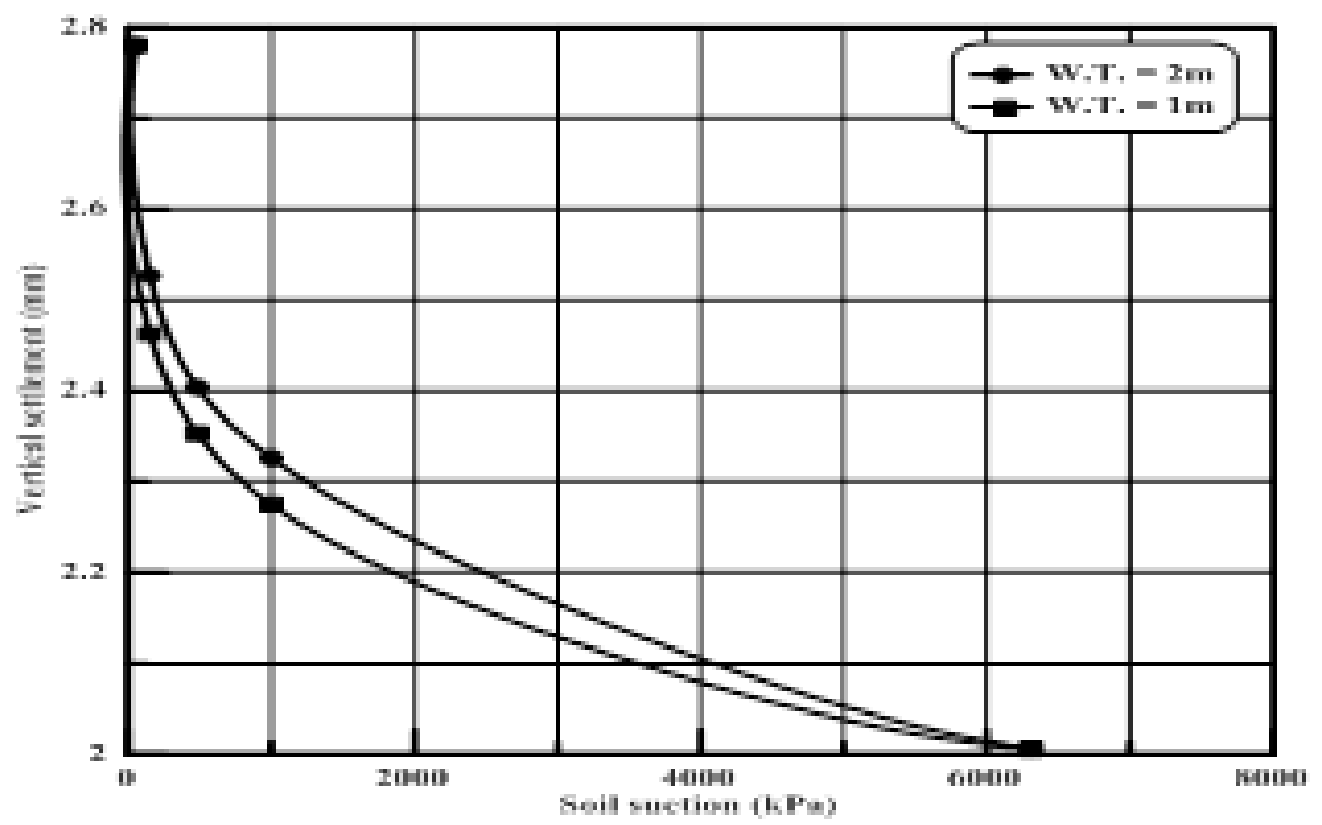

Figure 12: maximum vertical settlement for pavement system layer with soil suction for water depth $=\mathbf{2} \mathbf{m}$, $1 \mathrm{~m}$

Figures 13 and 14 show variation of negative pore water pressure with depth for different water table level and degree of consolidation. 


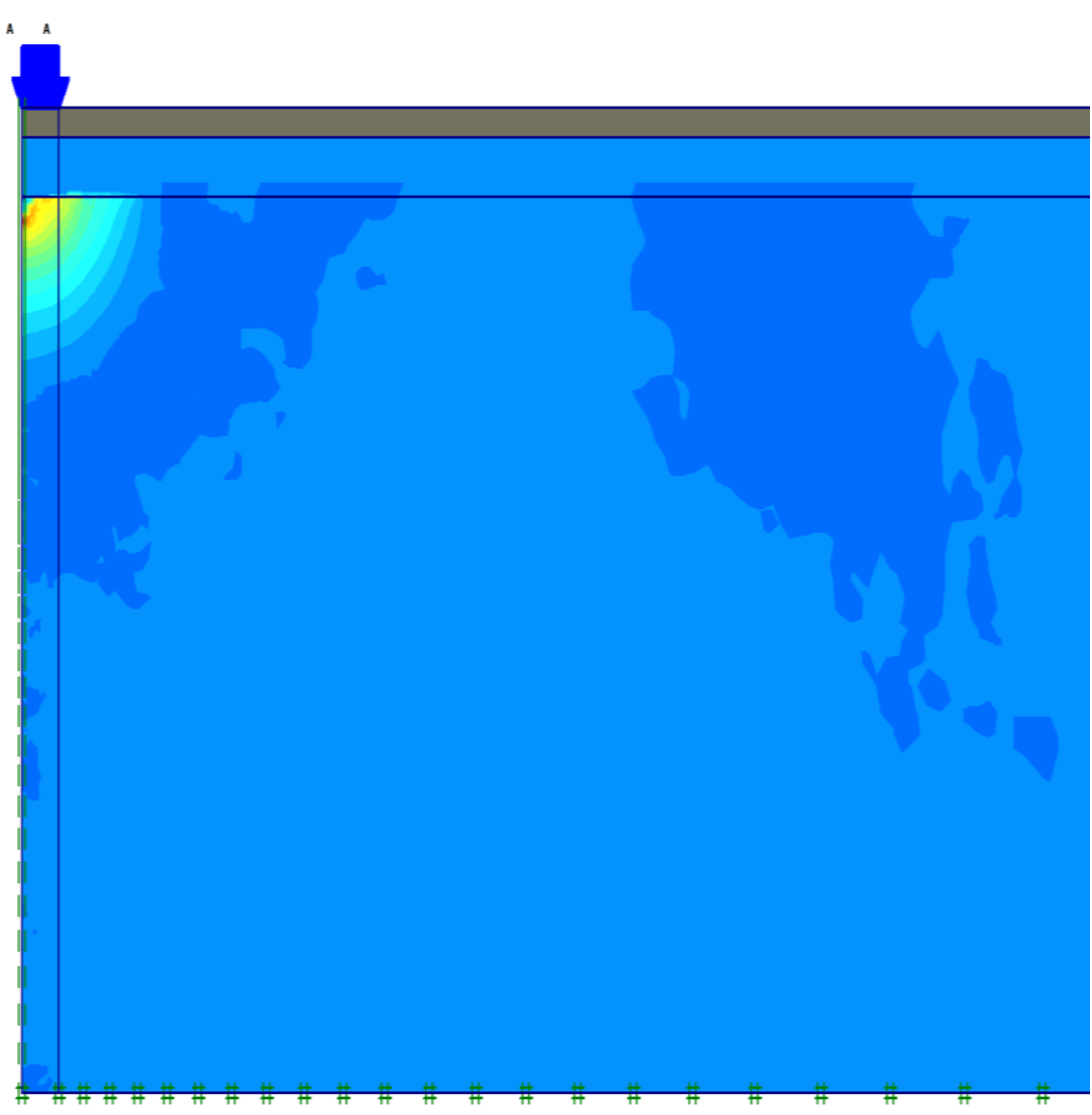

$\left[\mathrm{kN} / \mathrm{m}^{2}\right]$

\begin{tabular}{l}
-42.500 \\
-40.000 \\
-37.500 \\
-35.000 \\
-32.500 \\
-30.000 \\
-27.500 \\
-25.000 \\
\hline 22.500 \\
\hline 20.000 \\
\hline 17.500 \\
\hline 15.000 \\
\hline 12.500 \\
\hline 10.000 \\
\hline 7.500 \\
\hline 5.000 \\
\hline 2.500 \\
\hline 0.000 \\
\hline-2.500 \\
\hline-5.000 \\
\hline-7.500 \\
\hline-10.000 \\
\hline
\end{tabular}

Figure 13: variation of pore water pressure for pavement system layer with depth, $S=100 \%$, W.T. at the top of subgrade

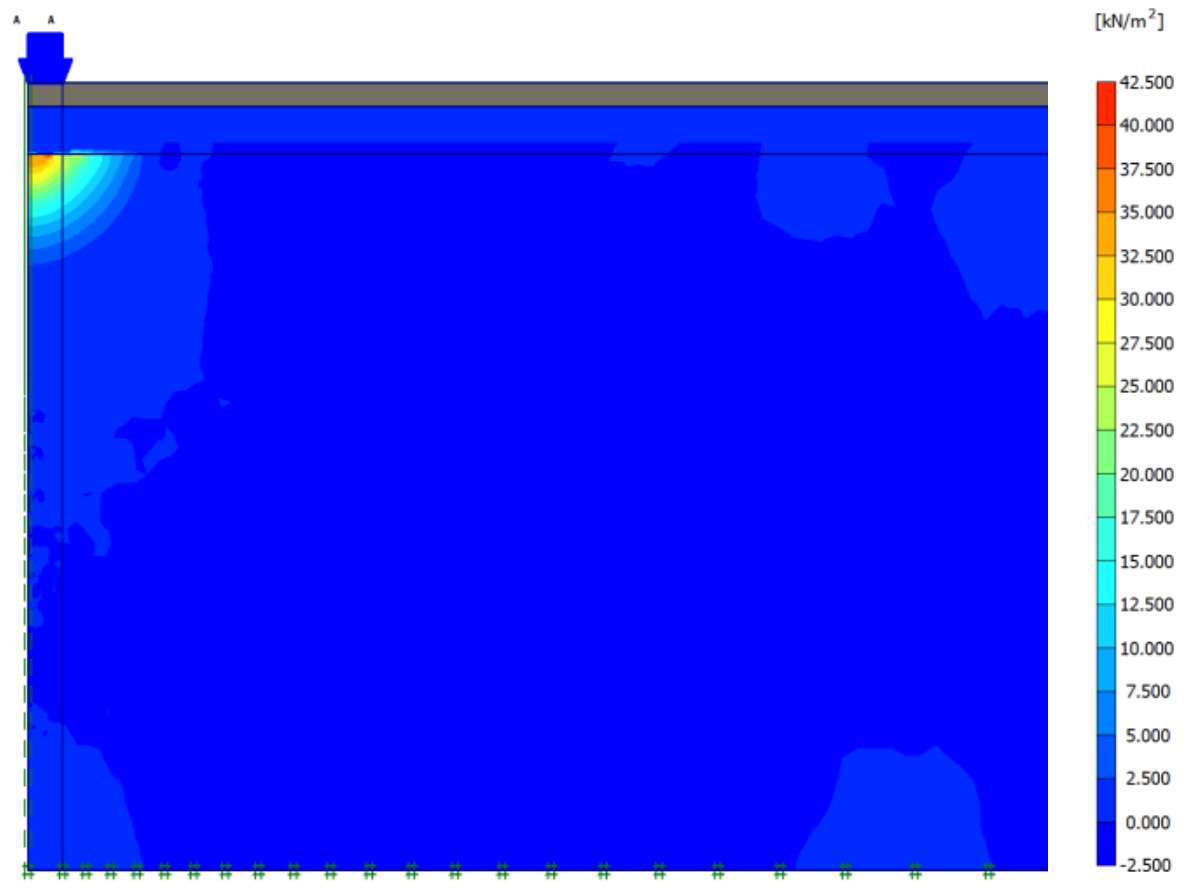

Figure 14: variation of pore water pressure for pavement system layer with depth, $S=70 \%$, W.T. $=2$ from top of subgrade 


\section{Conclusions}

From the analysis carried out plaxis program on pavement system layer the following points can be draw:

1. The vertical settlement closely similar at the beginning time then increased with time for water level at depth $1 \mathrm{~m}$ and $2 \mathrm{~m}$. The percentage reduction in settlement decreased by about $(11,15$, and $18 \%)$ for water table level $=1 \mathrm{~m},(9,13,16 \%)$ for water table level $=2 \mathrm{~m}$ and $(28 \%)$ for water table level $=3 \mathrm{~m}$ respectively, (i.e.) the vertical settlement is lower when the soil was unsaturated.

2. The vertical settlement increased linearly with applied stress and the effect of dynamic loading on pavement behavior is significant only for high stress amplitude.

3. The effect of degree of saturation on the vertical settlement is apparent at the lower value for water table level ( 1 and $2 \mathrm{~m}$ ).

4. The pore water pressure decreased with decreased of degree of saturation and development increases with depth and dynamic load.

5. A significant effect of unsaturation is obtained at the center line of pavement layer and limited far away the center line.

\section{Acknowledgment}

This work was supported by Almustansiriya University, Highway and Transportation Engineering Department, which is gratefully acknowledged.

\section{References}

[1]. Fredlund , D.G., and Rahardjo, H., Soil Mechanics for Unsaturated Soils, John Wiley \& Sone Inc. New York, United States of America, 1993.

[2]. Fredlund, D.G., and Morgenstrern, N.R., Stress State Variables for Unsaturated Soils, Geotechnical Engineering Journal. Division, ASCE, 103, (4), (1977), pp. 447466.

[3]. Fredlund, D.G., Morgenstern, N.R., and Wider, R.A., The Shear Strength of Unsaturated Soil, Canadian Geotechnical Journal, 15, (1978), pp. 313-321.

[4]. Fredlund , D.G., and Rahardjo, H., Soil Mechanics for Unsaturated Soils, John Wiley \& Sone Inc. New York, United States of America, (1993).

[5]. Fredlund, D.G., Xing, A., Equation for the Soil Water Characteristic Curve, Canadian Geotechnical Journal 31, (3), (1994), pp. $521-532$.
[6]. Fredlund, D. G., Unsaturated Soil Mechanics in Engineering Practice, Journal of Geotechnical and Geoenvironmental Engineering, ASCE, 132, (3), (2006), pp. $286-321$.

[7].Vanapalli, S. K. and Mohamed, F. M. O., Bearing Capacity of Model Footings in Unsaturated Soils, In Experimental Unsaturated Soil Mechanics, Springer Proceedings in Physics, Springer -Verlag Berlin Geidelberg, 112, (2007), pp. 483493.

[8]. Hamdy, F. and Ahmed M. H. (2014). 2D Plaxis finite element modeling of asphaltconcrete pavement reinforced with geogrid. Journal of Engineering Sciences Assiut University Faculty of Engineering, Vol. 42No. 6, November 2014, pp. 1336-1348.

[9]. Ntirenganya,N. ; Kalumba, D. and De Wet, M., An Investigation of the Interlayer Adhesion Strength in Deeper Layers of the Pavement Structure, International Journal of Innovative Research in Advanced Engineering (IJIRAE) Issue 08, 3, (2016).

[10]. Smith, G.N., and Smith, Ian, G.N., Elements of Soil Mechanics, Seventh edition, published by Blackwell Science, 1998.

[11]. Mohammed, H., A., Behavior Of Partially Saturated Soils Under Strip Footings in Selected Locations at Baghdad City, MS.c. thesis, at the Faculty of Engineering, Baghdad University, 2012.

[12]. Bowles, J.E., Foundation Analysis and Design" McGraw - Hill Book Company. Inc. New York, 1996, pp. 127.

[13]. Kazemian, S., Barghchi, M., Prasad, A., Maydi, H. and Huat, B.K., Reinforced pavement above trench under urban traffic load: Case study and finite element (FE) analysis." Journal of Scientific Research and Essay 5 (21), Nov.4, (2010). pp. 33133328.

[14]. Al-Jumaili, M., A., Finite Element Modelling of Asphalt Concrete Pavement Reinforced with Geogrid by Using 3-D Plaxis Software, International Journal of Materials Chemistry and Physics 2, (2), (2016), pp. 62-70.

[15]. Alex, A., Characterization of Unbound Granular Layers in Flexible Pavements, Report No. ICAR/502-3, Texas Transportation Institute, 2000. 